\title{
Protocol
}

\section{Study protocol of a single-arm pre-post study to assess the preliminary effectiveness and feasibility of a home-based bimodal prehabilitation program on preoperative aerobic fitness in high-risk patients scheduled for liver or pancreatic resection}

\author{
Annefleur E. M. Berkel ${ }^{1}$, Laura Van Wijk², Bart C. Bongers ${ }^{3,4}$, Job Van Der Palen ${ }^{5}$, \\ Carlijn I. Buis ${ }^{2}$, Muriel Reudink ${ }^{6}$, Mike S. L. Liem ${ }^{1}$, Gerrit D. Slooter6, \\ Nico L. U. Van Meeteren ${ }^{4,7}$, Joost M. Klaase ${ }^{2 *}$
}

\author{
${ }^{1}$ Department of Surgery, Medisch Spectrum Twente, Enschede, The Netherlands \\ ${ }^{2}$ Department of Surgery, University Medical Center Groningen, Groningen, Groningen, The Netherlands \\ ${ }^{3}$ Department of Nutrition and Movement Sciences, NUTRIM School of Nutrition and Translational Research in Metabolism, \\ Maastricht University, Maastricht, The Netherlands \\ ${ }^{4}$ Department of Epidemiology, Care and Public Health Research Institute, Maastricht University, Maastricht, The Netherlands \\ ${ }^{5}$ Department of Epidemiology, Medisch Spectrum Twente, Enschede, The Netherlands \\ ${ }^{6}$ Department of Surgery, Maxima Medical Center, Veldhoven, The Netherlands \\ ${ }^{7}$ Top Sector Life Sciences and Health (Health Holland), The Hague, The Netherlands
}

Received: 13 January 2020

Revised: 17 March 2020

Accepted: 19 March 2020

*Correspondence:

Dr. Joost M. Klaase,

E-mail: j.m.klaase@umcg.nl

Copyright: (c) the author(s), publisher and licensee Medip Academy. This is an open-access article distributed under the terms of the Creative Commons Attribution Non-Commercial License, which permits unrestricted non-commercial use, distribution, and reproduction in any medium, provided the original work is properly cited.

\section{ABSTRACT}

Background: Controversial evidence currently exists regarding the feasibility and effectiveness to improve preoperative aerobic fitness during home-based prehabilitation in patients scheduled for liver or pancreatic resection, whereas morbidity rates are high following these resections. The primary aim of this study is to evaluate the preoperative oxygen uptake $\left(\mathrm{VO}_{2}\right)$ at the ventilatory anaerobic threshold before and after a four-week home-based preoperative training program with nutritional supplementation in high-risk patients scheduled for elective liver or pancreatic resection. Secondary aims are to evaluate program feasibility, immune system function, cardiopulmonary exercise test responses, individual progression profiles on training responses, quality of life, and postoperative course. Methods: In this multicenter study with a pretest-posttest design, patients with a liver or pancreatic tumor scheduled for elective resection will be recruited. To select the high-risk fraction of this surgical population, their $\mathrm{VO}_{2}$ at the ventilatory anaerobic threshold should be $<11 \mathrm{ml} / \mathrm{kg} / \mathrm{min}$ for final inclusion. A planned total of 24 high-risk patients will participate in a four-week (three sessions per week) home-based bimodal prehabilitation program. The partly supervised home-based preoperative training program consists of individualized goal setting followed by titration of interval and endurance training on an advanced cycle ergometer, combined with functional task exercises. Additionally, patients will be given protein and vitamin/mineral supplementation.

Discussion: Effects of a partly supervised home-based bimodal prehabilitation regimen are unknown in high-risk patients opting for liver or pancreatic resection. Improved preoperative aerobic fitness might translate into improved postoperative outcomes and a reduced demand on care resources.

Trial Registration: The study is registered in the Netherlands Trial Registry (NL6151) and was approved by the Institutional Ethics Committee, Twente, Enschede, the Netherlands (P17-08).

Keywords: Aerobic fitness, Cardiopulmonary exercise testing, Cardiorespiratory fitness, Hepatopancreatobiliary surgery, Home-based training, Prehabilitation 


\section{INTRODUCTION}

Morbidity rates after resection of liver and pancreatic tumors are high. A recent study reported that $43 \%$ of the patients had a complicated postoperative course after major liver resection ( $\geq 3$ segments) and $26 \%$ after a minor liver resection ( $<3$ segments) for colorectal liver metastasis. ${ }^{1}$ Additionally, the Dutch Institute for Clinical Auditing (DICA) reported that between 2014 and 2018, $29 \%$ of the patient's developed a major complication after pancreaticoduodenectomy. ${ }^{2}$

Preoperative aerobic fitness has been found to have a consistent relation with postoperative outcome after major elective intra-abdominal surgery (e.g., morbidity). ${ }^{3-}$

6 Hence, adequate preoperative risk stratification is important to identify patients with a low aerobic fitness, as these patients have a higher risk for postoperative complications and therefore might benefit from prehabilitation. Previous studies consistently indicated that an oxygen uptake $\left(\mathrm{VO}_{2}\right)$ at the ventilatory anaerobic threshold $<11 \mathrm{ml} / \mathrm{kg} / \mathrm{min}$ and/or a $\mathrm{VO}_{2}$ at peak exercise $\left(\mathrm{VO}_{2 \text { peak }}\right)<18 \mathrm{ml} / \mathrm{kg} / \mathrm{min}$, as determined during a cardiopulmonary exercise test (CPET), are cut-off points to identify patients that have a higher risk for postoperative complications. ${ }^{3,7}$ Exercise prehabilitation has been reported to be able to preoperatively increase the physical fitness of patients scheduled for elective intraabdominal surgery, of which high-risk patients will benefit the most. ${ }^{11}$ In a recent study of Barberan-Garcia et al in high-risk patients who underwent elective major abdominal surgery, exercise prehabilitation not only improved preoperative aerobic fitness, but also resulted in a $51 \%$ reduction in postoperative complications compared to the usual care group. ${ }^{8-12}$

Most preoperative training programs were carried out under supervision in an outpatient clinic; however, a personalized exercise program in a home-based setting might enhance the participation rate, motivation, and adherence of (high-risk) patients, and has proven to be the preferred method for a prehabilitation program. ${ }^{11,13,14}$ Although several studies investigated the effects of exercise prehabilitation in liver and/or pancreatic resection and reported positive effects on physical fitness and postoperative morbidity, there is limited evidence addressing the feasibility and effectiveness of supervised home-based prehabilitation in these populations. ${ }^{9,12,15,16}$ Additionally, optimal nutrition during exercise is required, knowing the profound effects on the muscle protein turnover during exercise. ${ }^{17}$ Several studies already promote the combination of nutritional support with exercise for reaching an optimal effect. ${ }^{18,19}$ Finally, besides the positive effects of prehabilitation on physical fitness found in specific cases, the exact response of the immune system on prehabilitation prior to elective liver or pancreatic resection is unclear. ${ }^{9,12}$ In general, regular training reduces levels of systemic pro-inflammatory markers and increases the levels of anti-inflammatory factors. ${ }^{20}$ It remains however of interest to explore the effects of prehabilitation on immune system function as well.

\section{Study aims}

The primary aim of this study is to evaluate the preliminary effectiveness of a four-week home-based bimodal prehabilitation program on an advanced cycle ergometer in high-risk patients scheduled for elective liver or pancreatic resection to improve the preoperative $\mathrm{VO}_{2}$ at the ventilatory anaerobic threshold. Secondary aims are to evaluate the feasibility of this four-week home-based bimodal prehabilitation program, to evaluate the individual (preliminary) effect of prehabilitation on immune system function, to evaluate the (preliminary) effect of the prehabilitation program on other CPET values, to construct individual response profiles on the progression in aerobic fitness, to observe whether the prehabilitation program improves preoperative quality of life, and to describe the postoperative course in patients after elective liver or pancreatic resection; by collecting data on the surgical intervention and postoperative outcomes.

\section{METHODS}

\section{Study design}

This study is a multicenter feasibility study with a pretest-posttest design. The study will run till patient inclusion is completed (probably May 2020) at the hospitals Medisch Spectrum Twente (Enschede), Maxima Medical Center (Veldhoven and Eindhoven), and University Medical Center Groningen. In this manuscript, the latest version of the study protocol (version 5, January 2019) is presented. The study is approved by the Medical Ethics Committee Twente, the Netherlands (registration number P17-08, NL59702.044.16, April 2017), and is registered in the Netherlands Trial Register (NL6151). Protocol amendments need to be approved by the Medical Ethics Committee Twente.

\section{Participants}

A patient must meet the following inclusion criteria to be included: being diagnosed with a liver tumor (benign tumor, primary cancer, suspicion of a malignancy, or colorectal liver metastasis), premalignant pancreatic tumor, or (the suspicion of) a pancreatic malignancy, scheduled for liver (segmental resection or hemihepatectomy) or pancreatic surgery (pancreaticoduodenectomy, subtotal or total pancreatectomy) at Medisch Spectrum Twente, Maxima Medical Center, or University Medical Center Groningen, having a life expectancy of $>6$ months as estimated by the surgeon, 4) having a metabolic equivalent of task (MET) score $\leq 7$ on the veterans-specific activity questionnaire (VSAQ), indicating that the patient might have a reduced aerobic fitness and therefore might be at risk for postoperative complications, being able to perform a CPET, having provided consent to participate in the study, and having a 
$\mathrm{VO}_{2}$ at the ventilatory anaerobic threshold $<11 \mathrm{ml} / \mathrm{kg} / \mathrm{min}$ as measured at the baseline CPET. ${ }^{21}$ All patients not meeting these criteria will not be considered for inclusion.

\section{Recruitment}

All patients will be identified at multi-disciplinary oncology meetings, and will be evaluated at the outpatient clinic by the surgeon. Potentially eligible candidates (VSAQ score $\leq 7$ METs) will be given full details of the study, and will be invited to participate in the study. A few days later, they will be contacted by telephone to provide additional information about the trial. Furthermore, an appointment to obtain written informed consent and to perform baseline assessments (e.g., $\mathrm{VO}_{2}$ at the ventilatory anaerobic threshold for final inclusion) will be planned.

\section{Interventions}

\section{Home-based exercise prehabilitation}

All included high-risk patients will participate in a fourweek partly supervised and individually tailored homebased bimodal prehabilitation program prior to elective liver or pancreatic resection, which was developed using the CONTENT scale for therapeutic validity. ${ }^{22}$ The aim of the program is to increase the preoperative level of physical fitness, specifically aerobic fitness. Training frequency during the exercise prehabilitation part will be at least three sessions per week and training progress will be weekly titrated, on the base of progress in steep ramp test performance as an estimate of aerobic fitness. ${ }^{23}$ Every training session takes at least 30 minutes. The homebased training program consists of two sessions per week of moderate-to-high intensity interval training and one session per week of moderate-intensity endurance training (Table 1 and 2), twice a week combined with context-specific and person-tailored moderate-to-high intensity functional task exercises.

For the training sessions, an advanced cycle ergometer (Lode Corival, Lode BV, Groningen, the Netherlands) will be delivered at the patient's home. A community physical therapist will visit the patient at home to explain how the cycle ergometer works. Participating community physical therapists will be instructed about the use of the cycle ergometer and the functional exercise training concept, as well as about the goals and content of the training program by a training manual and by video consulting with a community physical therapist experienced with the training program. When necessary, they will contact an experienced community physical therapist and/or clinical exercise physiologist to discuss practical challenges. The physical therapist will visit the patient three times in week 1 , and once a week in week 2 , week 3, and week 4. Each week, a steep ramp test will be carried out by the patient under supervision of the physical therapist in order to individually set-up and optimize training intensity of the interval and endurance training sessions, as well as to monitor progression (titration) as advised by Glasziou et al. ${ }^{23}$ The physical therapist will check if the patient completes each training session, and will discuss these findings with the patient on a weekly base. Twice a week, the home-based interval training and endurance training will be combined with functional exercise training of activities of daily living of relevance for the individual patient according to Siemonsma et al. ${ }^{24}$ These exercises might include stairclimbing, sit to-stand exercises, outdoor cycling, outdoor walking and will be assembled in close collaboration between the physical therapist and the patient (when necessary assisted by an (in)formal caregiver).

Table 1: Overall training program structure.

\begin{tabular}{|c|c|c|c|c|}
\hline $\begin{array}{l}\text { Training } \\
\text { type }\end{array}$ & Phase & Duration & Intensity & Pedaling frequency \\
\hline \multirow{4}{*}{$\begin{array}{l}\text { Interval } \\
\text { training }\end{array}$} & Warm-up & 5 minutes & $20 \mathrm{~W}$ & $40-80$ revolutions/min \\
\hline & \multirow[b]{2}{*}{$\begin{array}{l}\text { Interval } \\
\text { session }\end{array}$} & \multirow[b]{2}{*}{20 minutes } & $\begin{array}{l}\text { Work interval intensity } \\
30 \text { seconds at } 60 \% \text { of steep ramp test } \mathrm{WR}_{\text {peak }}(\mathrm{W})^{\mathrm{a}}\end{array}$ & $60-100$ revolutions/ $\min$ \\
\hline & & & $\begin{array}{l}\text { Recovery interval intensity } \\
60 \text { seconds at } 20 \mathrm{~W} \\
\text { Alternating work-recovery intervals }\end{array}$ & $40-60$ revolutions/min \\
\hline & Recovery & 5 minutes & $20 \mathrm{~W}$ & $40-80$ revolutions/min \\
\hline \multirow{4}{*}{$\begin{array}{l}\text { Endurance } \\
\text { training }\end{array}$} & Warm-up & 7 minutes & $20 \%$ of steep ramp test $\mathrm{WR}_{\text {peak }}(\mathrm{W})^{\mathrm{a}}$ & $40-80$ revolutions/min \\
\hline & \multirow{2}{*}{$\begin{array}{l}\text { Endurance } \\
\text { interval } \\
\text { session }\end{array}$} & \multirow[b]{2}{*}{30 minutes } & $\begin{array}{l}\text { Moderate-intensity intervals }{ }^{\mathrm{b}} \\
40 \% \text { of steep ramp test } \mathrm{WR}_{\text {peak }}(\mathrm{W})^{\mathrm{a}}\end{array}$ & $60-100$ revolutions/min \\
\hline & & & $\begin{array}{l}\text { Low-intensity intervals }{ }^{\mathrm{b}} \\
20 \% \text { of steep ramp test } \mathrm{WR}_{\text {peak }}(\mathrm{W})^{\mathrm{a}} \\
\text { Alternating moderate- and low-intensity intervals }\end{array}$ & $40-60$ revolutions/min \\
\hline & Recovery & 3 minutes & $25 \%$ of steep ramp test $\mathrm{WR}_{\text {peak }}(\mathrm{W})^{\mathrm{a}}$ & $40-80$ revolutions/min \\
\hline
\end{tabular}

Abbreviation: $\mathrm{WR}_{\text {peak }}=$ peak work rate. ${ }^{\mathrm{a}}$ : the steep ramp test will be performed on a weekly base to objectively monitor training progress (titration) and to adjust training intensity accordingly. ${ }^{\text {b}}$ : see Table 2 for the weekly interval duration of the moderate- and low-intensity intervals of the endurance training sessions. 
Table 2: Weekly interval duration of the endurance training sessions.

\begin{tabular}{|lll|}
\hline Week & Duration of the moderate-intensity intervals (in sec) & Duration of the low-intensity intervals (in sec) \\
\hline $\mathbf{1}$ & 120 & 180 \\
\hline $\mathbf{2}$ & 140 & 160 \\
\hline $\mathbf{3}$ & 160 & 140 \\
\hline $\mathbf{4}$ & 180 & 120 \\
\hline
\end{tabular}

Table 3: Schedule of enrolment, interventions, and assessments.

\begin{tabular}{|c|c|c|c|c|c|}
\hline Study period & $\begin{array}{l}\text { Pre- } \\
\text { prehabilitation }\end{array}$ & Prehabilitation & $\begin{array}{l}\text { Post- } \\
\text { prehabilitation }\end{array}$ & Follow-up & \\
\hline \multirow[t]{2}{*}{ Timepoint } & Week & & & \multirow[t]{2}{*}{$\begin{array}{l}\text { Day } 7 \text { post- } \\
\text { surgery }\end{array}$} & \multirow[t]{2}{*}{$\begin{array}{l}\text { Day } 30 \text { post } \\
\text { surgery }\end{array}$} \\
\hline & $\mathbf{0}$ & 3 & 4 & & \\
\hline \multicolumn{6}{|l|}{ Enrolment } \\
\hline \multicolumn{6}{|l|}{ Eligibility screening } \\
\hline \multicolumn{6}{|l|}{ Informed consent } \\
\hline \multicolumn{6}{|l|}{$\begin{array}{l}\text { CPET, } \mathrm{VO}_{2} \text { at the VAT } \\
(\mathrm{ml} / \mathrm{kg} / \mathrm{min})\end{array}$} \\
\hline \multicolumn{6}{|l|}{ Intervention } \\
\hline \multicolumn{6}{|l|}{$\begin{array}{l}\text { Bi-modal home-based } \\
\text { prehabilitation }\end{array}$} \\
\hline \multicolumn{6}{|l|}{ Assessments } \\
\hline \multicolumn{6}{|l|}{ Baseline characteristics } \\
\hline \multicolumn{6}{|l|}{ VSAQ score (METs) } \\
\hline \multicolumn{6}{|l|}{ CPET } \\
\hline \multicolumn{6}{|l|}{$\mathrm{VO}_{2}$ at the $\operatorname{VAT}(\mathrm{ml} / \mathrm{kg} / \mathrm{min})$} \\
\hline \multicolumn{6}{|l|}{$\mathrm{VO}_{2 \text { peak }}(\mathrm{ml} / \mathrm{kg} / \mathrm{min})$} \\
\hline \multicolumn{6}{|l|}{ Feasibility } \\
\hline \multicolumn{6}{|l|}{ Blood sampling } \\
\hline \multicolumn{6}{|l|}{ IL-6, -8 , and -10} \\
\hline \multicolumn{6}{|l|}{ C-reactive protein } \\
\hline \multicolumn{6}{|l|}{ Tumor necrosis factor- $\alpha$} \\
\hline \multicolumn{6}{|l|}{ Steep ramp test, $\mathrm{WR}_{\text {peak }}(\mathrm{W})$} \\
\hline \multicolumn{6}{|l|}{$\begin{array}{l}\text { Quality of life questionnaire, } \\
\text { SF-36 }\end{array}$} \\
\hline \multicolumn{6}{|l|}{$\begin{array}{l}\text { Health status questionnaire, } \\
\text { EQ-5D }\end{array}$} \\
\hline \multicolumn{6}{|l|}{ Physical activity diary } \\
\hline \multicolumn{6}{|l|}{ Nutritional diary } \\
\hline Appreciation questionnaire & & & O & & \\
\hline \multicolumn{6}{|l|}{ Postoperative outcomes } \\
\hline \multicolumn{4}{|l|}{$\begin{array}{l}\text { Time to recovery of physical } \\
\text { functioning (days) }\end{array}$} & 0 & 0 \\
\hline Postoperative complications & & & & 0 & 0 \\
\hline $\begin{array}{l}\text { Length of hospital stay } \\
\text { (days) }\end{array}$ & & & & 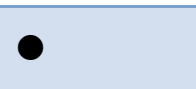 & 0 \\
\hline
\end{tabular}

Abbreviations: CPET=cardiopulmonary exercise test; EQ-5D=EuroQol 5D; MET=metabolic equivalent of task; SF-36=short-form 36; $\mathrm{VAT}=$ ventilatory anaerobic threshold; $\mathrm{VO}_{2}=$ oxygen uptake; $\mathrm{VO}_{2 \text { peak }}=$ oxygen uptake at peak exercise; VSAQ=veterans-specific activity questionnaire; $\mathrm{WR}_{\text {peak }}=$ peak work rate.

\section{Nutritional supplementation}

To stimulate muscle protein synthesis, participants will be provided with protein supplementation immediately following exercise and (approximately 30 minutes) before sleep, providing a standard dosage of $30 \mathrm{~g}$ of a high-quality (whey and casein) protein that contains at least $10 \mathrm{~g}$ of essential amino acids, of which 2-3 g Leucine. Since vitamin D is associated with muscle mass and muscle strength, it will be supplemented daily according to guidelines of the Health Council of the Netherlands (10 $\mu \mathrm{g}$ for woman aged 50-69 years, for men 
$<70$ years and women $<50$ years with colored skin and/or little sun exposure, and $20 \mu \mathrm{g}$ for women and men aged 70 years or older). ${ }^{25,26}$ To prevent patients from having a deficiency of vitamins and minerals below recommended doses before surgery, all other vitamins and minerals are supplied in a multivitamin/mineral supplement containing $50 \%$ of the recommended daily allowance. ${ }^{27}$

\section{Measurements}

All patients will participate in a series of outcome measure assessments at baseline, each week during the four-week prehabilitation program, and after completion of the program (Table 3 ).

\section{Cardiopulmonary exercise test}

A CPET will be performed by the patient at baseline and after completion of the prehabilitation program to assess aerobic fitness. At baseline, CPET performance is used to select and thereupon invite eligible high-risk patients to participate in the study $\left(\mathrm{VO}_{2}\right.$ at the ventilatory anaerobic threshold $<11 \mathrm{ml} / \mathrm{kg} / \mathrm{min})$. After completion of the program, the CPET will be used to assess the preliminary effectiveness of the four weeks of home-based bimodal prehabilitation to improve $\mathrm{VO}_{2}$ at the ventilatory anaerobic threshold and other CPET variables.

The CPET will be performed using an electronically braked cycle ergometer in upright position (Ergoline, Ergoselect 100, Bitz, Germany at Medisch Spectrum Twente, Lode Corival, Lode BV, Groningen, the Netherlands at Maxima Medisch Centrum, and Monark LC6, Monark Exercise AB, Vansbro, Sweden at University Medical Center Groningen). The CPET consists of a two-minute resting phase, a three-minute unloaded warm-up phase, an incremental phase with constant work rate increments of 5,10 , or $15 \mathrm{~W} / \mathrm{min}$, aimed at reaching a maximal effort within eight to twelve minutes, and a five-minute recovery phase. Throughout the warm-up and incremental phase, patients will have to maintain a pedaling frequency between 60 and 80 revolutions/min. The protocol continues until the patient's pedaling frequency falls definitely $<60$ revolutions/min, despite strong verbal encouragement.

During the CPET, the patient breathes through a facemask (Hans Rudolph, Shawnee, USA) connected to a Triple V volume transducer to calculate breath-by-breath minute ventilation, $\mathrm{VO}_{2}$, carbon dioxide production, and the respiratory exchange ratio (RER) averaged at tensecond intervals (Oxycon Pro, Jaeger, Höchberg, Germany at Medisch Spectrum Twente, Vyntus CPX, CareFusion, Höchberg, Germany at Maxima Medisch Centrum, and Quark CPET, Cosmed, Roma, Italy at University Medical Center Groningen). Flow-volume (three-liter syringe, Hans Rudolph, Shawnee, KS, USA) and gas calibration (ambient air and a gas mixture of 15 or $16 \%$ oxygen and $5 \%$ carbon dioxide) are performed manually before each test. Heart rate (HR), twelve-lead electrocardiography, blood pressure, and pulse oximetry are continuously monitored.

Interpretation of CPETs will be performed by an experienced clinical exercise physiologist (BB). A test will be considered to be at or near the maximal level when participants show clinical signs of intense effort (e.g., unsteady biking, sweating, clear unwillingness to continue exercising despite strong encouragement), are unable to maintain the required pedalling speed, and when at least one of the following criteria is met: an HR at peak exercise $\left(\mathrm{HR}_{\text {peak }}\right)>95 \%$ of predicted (predicted HR [beats $/ \mathrm{min}]=210-(0.8 \times$ age [years] $))$ or an RER at peak exercise $\left(\operatorname{RER}_{\text {peak }}\right)>1.10$. Absolute values at peak exercise will be calculated as the average value over the last 30 seconds prior to termination of the test. $H_{R}$ peak is defined as the highest HR achieved during the last 30 seconds of the CPET. The ventilatory anaerobic threshold will be defined by using the V-slope method ${ }^{28}$ and the ventilatory equivalents method. ${ }^{29,30}$

\section{Steep ramp test}

The steep ramp test, a short time maximal exercise test on a cycle ergometer, will be used to individually set-up and optimize training intensity of the interval and endurance training sessions, as well as to monitor progression in aerobic fitness throughout the prehabilitation program (titration). ${ }^{31}$ To maintain a sufficient training stimulus, training intensity of the interval and endurance training sessions will be adjusted weekly based on steep ramp test performance.

The steep ramp test will be carried out on the advanced cycle ergometer in upright position (Lode Corival, Lode BV, Groningen, the Netherlands), using a modified protocol to increase feasibility in unfit (elderly) patients. The test consists of a two-minute unloaded warm-up phase, an incremental phase with constant work rate increments of $10 \mathrm{~W}$ every 10 seconds ( $1 \mathrm{~W}$ every second), and a three-minute recovery phase. $^{32}$ The importance of a maximal effort will be explained clearly to the patient and throughout the test the physical therapist will verbally encourage the patient. During the warm-up and incremental phase, patients will have to maintain a pedaling frequency between 60 and 80 revolutions/min. The protocol continues until the patient's pedaling frequency falls definitely $<60$ revolutions/min, despite strong verbal encouragement. ${ }^{32}$ The main outcome of the steep ramp test is the achieved peak work rate $\left(\mathrm{WR}_{\text {peak }}\right)$. After peak exercise, the patient will be asked to complete a cool-down phase for at least two minutes consisting of unloaded pedaling $(0 \mathrm{~W})$ at a frequency of about 40 revolutions/min.

\section{Feasibility of the prehabilitation program}

Consistent with previous studies examining the feasibility of novel exercise activities for a variety of at-risk populations, feasibility of the home-based bimodal prehabilitation program will be determined by 
participation rate and reasons for non-participation, the registration of the number and severity of adverse events, adherence to the program, and drop-out rate and reasons for drop-out. ${ }^{33-35}$ Adverse events will be recorded by the community physical therapist. Data concerning training intensity and duration from each interval and endurance training session will be displayed at the cycle ergometer following a training session, and recorded by the physical therapist or by the patient in case of an unsupervised training session. A patient diary will be used to assess the patient's other daily physical activities (e.g. walking, cycling, household activities), and their experienced symptoms. Moreover, patient motivation will be measured before and after each training session by asking patients to rate their motivation to complete the training session on a scale from 0 to 10 . After the program, the patient will also be asked to fill out a patient appreciation questionnaire based on a previous study. ${ }^{38} \mathrm{~A}$ food diary will be used to assess the patient's compliance with the intake of the protein and vitamin or mineral supplementation.

\section{Blood samples}

To assess the effect of the four-week bimodal prehabilitation program on the immune system, blood samples will be taken at two moments during this study. Blood samples will be collected within 3-7 days after the CPET at baseline and prior to the CPET after completion of the prehabilitation program to quantify the immune response during to the exercise program. Levels of interleukin-6, -8, and -10, C-reactive protein, and tumor necrosis factor- $\alpha$ will be assessed. For every patient a separate blood sample will be drawn for storage and future analyses. Blood samples from a superficial vein in the forearm using venipuncture will be taken in the participating clinical centers by well-trained nurses. Blood samples will be centrifuged and plasma will be stored at $-80^{\circ} \mathrm{C}$ until assayed for future analysis. Blood samples will be stored for a maximum of five years in the biobank of the participating clinical center. Blood samples will be run in duplicate and analyzed using enzyme-linked immunosorbent assay at the end of the study.

\section{Questionnaires}

At the first clinic attendance, the patient will receive a quality of life and health status questionnaire to fill out at home. The short-form 36 (SF-36) will be used to assess quality of life. ${ }^{36}$ Health status will be measured by using the EuroQol five-dimensional questionnaire (EQ-5D). ${ }^{37}$ The community physical therapist will ask the patient to fill out these questionnaires for the second time after the four-week training period, to observe whether the prehabilitation program improves preoperative quality of life and health status.

\section{Study outcomes}

\section{Primary study parameter/endpoint}

The primary endpoint of this study is the increase in preoperative $\mathrm{VO}_{2}$ at the ventilatory anaerobic threshold following the four-week home-based bimodal prehabilitation program in high-risk patients (those with a $\mathrm{VO}_{2}$ at the ventilatory anaerobic threshold $<11$ $\mathrm{ml} / \mathrm{kg} / \mathrm{min}$ ) scheduled for elective liver or pancreatic resection.

\section{Secondary study parameters/endpoints}

Secondary endpoints of this study are feasibility of the four-week home-based prehabilitation program in highrisk patients, as measured by participation rate and reasons for non-participation, the registration of the number and severity of adverse events, adherence to the program, drop-out rate and reasons for drop-out, motivation, and patient appreciation, (preliminary) effects of prehabilitation on the immune system by measuring levels of interleukin-6, -8 , and -10, C-reactive protein, and tumor necrosis factor- $\alpha$ prior to the first and second CPET, the (preliminary) effect of the prehabilitation program on other CPET variables, such as $\mathrm{VO}_{2 \text { peak }}$ and the oxygen uptake efficiency slope, individual response profiles on the progression in aerobic fitness throughout the prehabilitation program as estimated on a weekly base (titration) by steep ramp test performance, (preliminary) effects of bimodal prehabilitation on quality of life as measured by the SF-36 questionnaire, on health condition by the EQ-5D health questionnaire, and the postoperative course in patients after elective liver or pancreatic resection, by collecting data on the surgical intervention and postoperative outcomes (e.g., morbidity by using the Clavien-Dindo classification, mortality, length of stay). ${ }^{39}$

\section{Other study parameters}

Preoperative factors that could be associated with physical fitness will be recorded as well; these include age, sex, body mass, body height, body mass index, nutritional status (short nutritional assessment questionnaire), smoking, location and type of the tumor, American Society of Anesthesiologists score, and Charlson comorbidity index.

\section{Data analysis}

\section{Sample size calculation}

In this study, a continuous response variable $\left(\mathrm{VO}_{2}\right.$ at the ventilatory anaerobic threshold) from matched pairs of study participants will be used. We hypothesize that prehabilitation will improve the preoperative $\mathrm{VO}_{2}$ at the ventilatory anaerobic threshold by $1.5 \mathrm{ml} / \mathrm{kg} / \mathrm{min}$ in patients with a low aerobic fitness scheduled for elective liver or pancreatic resection, based on the study of Dunne et al. ${ }^{15}$ Prior data indicate that the difference in the 
response of matched pairs is normally distributed with a standard deviation of $2.5 \mathrm{ml} / \mathrm{kg} / \mathrm{min}$. If the true difference in the mean response of matched pairs is $1.5 \mathrm{ml} / \mathrm{kg} / \mathrm{min}$, 24 participants need to be included to be able to reject the null hypothesis that this response difference is zero with a probability (power) of 0.80 . The type I error probability associated with this test of this null hypothesis is 0.05 .

\section{Procedures for data checking and entering}

Data will be entered in the Statistical Package for the Social Sciences for Windows (version 23.0; IBM, SPSS Inc., Chicago, IL, USA). Variables will be checked for the number of missing, impossible, or improbable values, prior to statistical analysis. In case of improbable or impossible values, the patient's data file will be checked. Descriptive statistics will be calculated for all variables, and distributional assumptions will be checked. Due to the low risk nature of the intervention, the research ethics committee determined that a data monitoring committee was not required.

\section{Statistical analysis}

Data will be presented as mean and standard deviation or as median and interquartile range, as appropriate. Categorical data will be summarized by frequency and percentage within each cohort. Analysis will be performed according to the intention-to-treat principle. To evaluate the preliminary effectiveness of the fourweek home-based bimodal prehabilitation program, the difference in the $\mathrm{VO}_{2}$ at the ventilatory anaerobic threshold before the start of the training and after four weeks of prehabilitation will be analyzed using a paired samples t-test or Wilcoxon signed rank test, as appropriate. A repeated measurements analysis (mixed models in SPSS) will be performed to assess changes over time in continuous variables. To evaluate the feasibility of the four-week home-based bimodal prehabilitation program, adherence or compliance, adverse events, motivation, and patient appreciation will be described by use of descriptive statistics. To analyze changes in biomarkers and other CPET variables before and after prehabilitation the paired samples t-test or Wilcoxon signed rank test, as appropriate, will be used. A repeated measurements analysis (mixed models in SPSS) will be performed to assess changes over time in continuous variables of the steep ramp test. The differences between quality of life measures before start of the training and after four weeks of prehabilitation will be analyzed with the paired samples t-test or Wilcoxon test, as appropriate. Descriptive statistics will be used to present data on perioperative variables and postoperative progress. $\mathrm{P}$ values $<0.05$ will be considered statistically significant.

\section{DISCUSSION}

Surgery is an important treatment modality for patients with liver or pancreatic tumors; however, perioperative morbidity is high, especially in patients scheduled for liver or pancreatic surgery with a low aerobic fitness. ${ }^{1,2,4,5}$ Enhancing preoperative physical fitness of these high-risk patients may improve their postoperative outcomes. Dunne et al showed that a four-week supervised hospitalbased exercise prehabilitation program improved the $\mathrm{VO}_{2}$ at the ventilatory anaerobic threshold on average with 1.5 $\mathrm{ml} / \mathrm{kg} / \mathrm{min} \quad(\mathrm{p}=0.023)$ before liver resection in the intervention group, with no statistically significant difference in any postoperative outcomes compared to the control group. ${ }^{15}$ In a study in high-risk patients undergoing elective major abdominal surgery, a combination of unsupervised home-based and supervised hospital-based exercise prehabilitation was found to be a protective factor for postoperative complications, with a $51 \%$ reduction in the number of patients with postoperative complications (relative risk of 0.5 ; $\mathrm{p}=0.001) .{ }^{12}$ Recently however, it was found that the most reported barrier to participate in a prehabilitation program was related to transportation (e.g., paying for parking, arranging transportation), besides finding the time. ${ }^{14}$ An important next step is therefore to improve the participation rate and adherence of high-risk patients with respect to prehabilitation programs in order to ensure the most vulnerable patients are empowered to engage. Indeed, high-risk patients, who are often older and frailer, are less likely to participate in a hospital-based training program, than in a home-based training program. ${ }^{11,14}$ Though, there are only a few studies available that investigated the effects of home-based prehabilitation. ${ }^{9}$ Nakajima et al recently reported that an unsupervised home-based exercise prehabilitation program improved physical fitness (median 6-minute walk test distance improved from 530 to $554 \mathrm{~m}$; $\mathrm{p}<0.001$ ) before hepatopancreatobiliary surgery in the intervention group, with merely a statistically significant reduction in postoperative length of stay compared to the control group. ${ }^{10}$ In general, currently described home-based prehabilitation programs were not supervised and not targeted at high-risk patients, ${ }^{9}$ probably limiting therapy adherence and effectiveness.

In addition to objectively selecting high risk patients, other strengths of the present study are the clear description of the study design and prehabilitation program, the use of validated measurement instruments, the assessment of the effect of the prehabilitation program on the immune system, and the weekly adjustment of the training program to the training progression of each individual patient, based upon the results of the steep ramp test. Moreover, the four-week (partly) supervised prehabilitation program will be performed at the patient's home, which minimizes the load for the patients as this study aims to reach even the frailest patients who are not capable or unwilling to visit an outpatient clinic. To gain insight in patient adherence, data of each exercise session on the advanced cycle ergometer will be noted by the physical therapist or by the patient in case of an unsupervised training session. Additionally, to achieve optimal training responses, all 
patients receive protein supplementation to reach a net positive protein balance. ${ }^{18}$ However, not only adequate protein intake is important, also the deficiency of other nutrients in patients should be investigated. Therefore, nutritional screening and assessment in a prehabilitation program is recommended, to diagnose, treat, and prevent malnutrition. ${ }^{19}$ The current study can help to identify implementation problems and to optimize a home-based prehabilitation program, which will be valuable for a future larger (implementation) study. The benefits of improved aerobic fitness, if the underlying hypothesis is correct, might translate into better postoperative outcomes and a reduced demand on hospital resources. ${ }^{40}$

\section{ACKNOWLEDGEMENTS}

We would like to thank Hayke Kotte (physical therapist, Fysio Twente, Enschede, the Nederland), Paul Weltevreden (physical therapist, FIT clinic, Enschede, the Nederland) and Ellis van Zutphen (physical therapist, Paramedics, Assen, the Nederland) for their contribution to the training program of the study protocol. We would also like to thank all involved community physical therapists who contributed to this study by supervising included patients.

\section{Funding: No funding sources}

Conflict of interest: None declared

Ethical approval: The study was approved by the Institutional Ethics Committee, Twente, Enschede, the Netherlands (P17-08) and is registered in the Netherlands Trial Registry (NL6151)

\section{REFERENCES}

1. Van der Werf LR, Kok NFM, Buis CI, Grünhagen DJ, Hoogwater FJH, Swijnenburg RJ, et al. Implementation and first results of a mandatory, nationwide audit on liver surgery. HPB (Oxford). 2019;21(10):1400-10.

2. Dutch Institute for Clinical Auditing (DICA) Leiden. DICA jaarrapportage 2018: Dutch Pancreatic Cancer Audit (DPCA). Available at: https://dica.nl/jaarrapportage-2018/dpca. Accessed on 02 September 2019.

3. Wilson RJ, Davies S, Yates D, Redman J, Stone M.. Impaired functional capacity is associated with allcause mortality after major elective intra-abdominal surgery. Br J Anaesth. 2010;105(3):297-303.

4. Junejo MA, Mason JM, Sheen AJ, Bryan A, Moore J, Foster P, et al. Cardiopulmonary exercise testing for preoperative risk assessment before pancreaticoduodenectomy for cancer. Ann Surg Oncol. 2014;21(6):1929-36.

5. Junejo MA, Mason JM, Sheen AJ, Moore J, Foster $\mathrm{P}$, Atkinson $\mathrm{D}$, et al. Cardiopulmonary exercise testing for preoperative risk assessment before hepatic resection. Br J Surg. 2012;99(8):1097-104.

6. Moran J, Wilson F, Guinan E. McCormick P, Hussey J, Moriarty J, et al. Role of cardiopulmonary exercise testing as a risk-assessment method in patients undergoing intra-abdominal surgery: a systematic review. Br J Anaesth. 2016;116(2):17791.

7. Older P, Smith R, Courtney P, Hone R. Preoperative evaluation of cardiac failure and ischemia in elderly patients by cardiopulmonary exercise testing. Chest. 1993;104(3):701-4.

8. Bruns ER, van den Heuvel B, Buskens CJ, et al. The effects of physical prehabilitation in elderly patients undergoing colorectal surgery: a systematic review. Colorectal Dis. 2016;18(8):O267-77.

9. Thomas G, Tahir MR, Bongers BC, van Duijvendijk P, Festen S, Wassenaar EB, et al. Prehabilitation before major intra-abdominal cancer surgery: A systematic review of randomised controlled trials. Eur J Anaesthesiol. 2019;36(12):933-45.

10. Nakajima H, Yokoyama $Y$, Inoue $T$, Nagaya $M$, Mizuno Y, Kadono I, et al. Clinical Benefit of Preoperative Exercise and Nutritional Therapy for Patients Undergoing Hepato-Pancreato-Biliary Surgeries for Malignancy. Ann Surg Oncol. 2019;26(1):264-72.

11. Bongers BC, Punt IM, van Meeteren NL. On Prehabilitation: The emperor's new clothes or a new arena for physical therapists? Phys Ther. 2018;12:127-30.

12. Barberan-Garcia A, Ubre M, Roca J, Lacy AM, Burgos F, Risco R, et al. Personalised Prehabilitation in High-risk Patients Undergoing Elective Major Abdominal Surgery: A Randomized Blinded Controlled Trial. Ann Surg. 2018;267(1):50-6.

13. Driessen EJ, Peeters ME, Bongers BC, Maas HA, Bootsma GP, van Meeteren NL, et al. Effects of prehabilitation and rehabilitation including a homebased component on physical fitness, adherence, treatment tolerance, and recovery in patients with non-small cell lung cancer: A systematic review. Crit Rev Oncol Hematol. 2017;114:63-76.

14. Ferreira V, Agnihotram RV, Bergdahl A, van Rooijen SJ, Awasthi R, Carli F, et al. Maximizing patient adherence to prehabilitation: what do the patients say? Support Care Cancer. 2018;26(8):2717-23.

15. Dunne DF, Jack S, Jones RP, Jones L, Lythgoe DT, Malik HZ, et al. Randomized clinical trial of prehabilitation before planned liver resection. $\mathrm{Br} \mathrm{J}$ Surg. 2016;103(5):504-12.

16. Ngo-Huang A, Parker NH, Wang X, Petzel MQB, Fogelman D, Schadler KL, et al. Home-based exercise during preoperative therapy for pancreatic cancer. Langenbecks Arch Surg. 2017;402(8):117585.

17. Burd NA, Tang JE, Moore DR, Phillips SM. Exercise training and protein metabolism: influences of contraction, protein intake, and sexbased differences. J Appl Physiol (1985). 2009;106(5):1692-701. 
18. Deutz NE, Bauer JM, Barazzoni R, Biolo G, Boirie Y, Bosy-Westphal A, et al. Protein intake and exercise for optimal muscle function with aging: recommendations from the ESPEN Expert Group. Clin Nutr. 2014;33(6):929-36.

19. Gillis C, Wischmeyer PE. Pre-operative nutrition and the elective surgical patient: why, how and what? Anaesthesia. 2019;74:27-35.

20. Sallam N, Laher I. Exercise Modulates Oxidative Stress and Inflammation in Aging and Cardiovascular Diseases. Oxid Med Cell Longev. 2016;2016:7239639.

21. Snowden CP, Prentis JM, Anderson HL, Roberts DR, Randles D, Renton M, et al. Submaximal cardiopulmonary exercise testing predicts complications and hospital length of stay in patients undergoing major elective surgery. Ann Surg. 2010;251(3):535-41.

22. Hoogeboom TJ, Oosting E, Vriezekolk JE, Veenhof C, Siemonsma PC, de Bie RA, et al. Therapeutic validity and effectiveness of preoperative exercise on functional recovery after joint replacement: a systematic review and meta-analysis. PLoS One. 2012;7(5):e38031.

23. Glasziou P, Irwig L, Mant D. Monitoring in chronic disease: a rational approach. BMJ. 2005;330(7492):644-8.

24. Siemonsma PC, Blom JW, Hofstetter H, van Hespen ATH, Gussekloo J, Drewes YM, et al. The effectiveness of functional task exercise and physical therapy as prevention of functional decline in community dwelling older people with complex health problems. BMC Geriatr. 2018;18(1):164,0180859-3.

25. Salles J, Chanet A, Giraudet C, Patrac V, Pierre P, Jourdan $\mathrm{M}$, et al. 1,25(OH)2-vitamin D3 enhances the stimulating effect of leucine and insulin on protein synthesis rate through $\mathrm{Akt} / \mathrm{PKB}$ and mTOR mediated pathways in murine $\mathrm{C} 2 \mathrm{C} 12$ skeletal myotubes. Mol Nutr Food Res. 2013;57(12):213746.

26. Voedingscentrum. Vitamine D. Available at: https://www.voedingscentrum.nl/encyclopedie/vita mine-d.aspx. Accessed on 2 September 2019.

27. van Rooijen S, Carli F, Dalton S. Multimodal prehabilitation in colorectal cancer patients to improve functional capacity and reduce postoperative complications: the first international randomized controlled trial for multimodal prehabilitation. BMC Cancer. 2019;19(1):98,0185232-6.

28. Beaver WL, Wasserman K, Whipp BJ. A new method for detecting anaerobic threshold by gas exchange. J Appl Physiol (1985). 1986;60(6):20207.

29. Borley NR, Achan V. Respiratory Physiology. Instant Physiology. Blackwell Science; 2000.

30. American Thoracic Society, American College of Chest Physicians. ATS/ACCP Statement on cardiopulmonary exercise testing. Am J Respir Crit Care Med. 2003;167(2):211-77.

31. Bongers BC, Takken T. The paediatric version of the steep ramp test. J Physiother 2014;60(2):113.

32. Van Beijsterveld CA, Bongers BC, Den Dulk M. The association between preoperative physical functioning and short-term postoperative outcomes: a cohort study of patients undergoing elective hepatic resection. HPB (Oxford). 2019;21(10):136270.

33. Fien S, Henwood T, Climstein M. Feasibility and benefits of group-based exercise in residential aged care adults: a pilot study for the GrACE programme. Peer J. 2016;4:e2018.

34. Bossers WJ, Scherder EJ, Boersma F. Feasibility of a combined aerobic and strength training program and its effects on cognitive and physical function in institutionalized dementia patients. A pilot study. PLoS One. 2014;9(5):e97577.

35. Cheema BS, Davies TB, Stewart M. The feasibility and effectiveness of high-intensity boxing training versus moderate-intensity brisk walking in adults with abdominal obesity: a pilot study. BMC Sports Sci Med Rehabil. 2015;7:3,1847-7-3.

36. Aaronson NK, Muller M, Cohen PD. Translation, validation, and norming of the Dutch language version of the SF-36 Health Survey in community and chronic disease populations. J Clin Epidemiol. 1998;51(11):1055-68.

37. Brazier J, Jones N, Kind P. Testing the validity of the Euroqol and comparing it with the SF-36 health survey questionnaire. Qual Life Res. 1993;2(3):16980.

38. Dronkers JJ, Lamberts H, Reutelingsperger IM. Preoperative therapeutic programme for elderly patients scheduled for elective abdominal oncological surgery: a randomized controlled pilot study. Clin Rehabil. 2010;24(7):614-22.

39. Bongers BC, Berkel AE, Klaase JM. An evaluation of the validity of the pre-operative oxygen uptake efficiency slope as an indicator of cardiorespiratory fitness in elderly patients scheduled for major colorectal surgery. Anaesthesia. 2017;72(10):120616.

40. Barberan-Garcia A, Ubre M, Pascual-Argente N. Post-discharge impact and cost-consequence analysis of prehabilitation in high-risk patients undergoing major abdominal surgery: secondary results from a randomised controlled trial. $\mathrm{Br} \mathrm{J}$ Anaesth. 2019;123(4):450-6.

Cite this article as: Berkel AEM, Wijk LV, Bongers BC, Palen JVD, Buis CI, Reudink M, et al. Study protocol of a single-arm pre-post study to assess the preliminary effectiveness and feasibility of a homebased bimodal prehabilitation program on preoperative aerobic fitness in high-risk patients scheduled for liver or pancreatic resection. Int J Clin Trials 2020;7(2):10311. 